\title{
Home Deliveries in Rwinkwavu District Hospital, Rwanda: Factor Associated with Recurrence of the Practice
}

\author{
Muhire A', Mukarwego B', Muhimba I ${ }^{1,2}$, \\ Bizimana $\mathrm{GE}^{1,3}$, Bagwaneza $\mathrm{T}^{4}$ and Rutayisire $\mathrm{E}^{1 *}$ \\ ${ }^{1}$ Department of Public Health, Mount Kenya University, \\ Rwanda \\ ${ }^{2}$ Mugonero Hospital, Ministry of Health, Rwanda \\ 3 J igsaw Consult/ Refugee Education, UK \\ ${ }^{4}$ Rwanda Biomedical Center, Rwanda \\ *Corresponding author: Erigene Rutayisire, Public \\ Health Department, Mount Kenya University, Kigali, \\ Rwanda
}

Received: J une 09, 2021; Accepted: July 07, 2021;

Published: July 14, 2021

\begin{abstract}
Home delivery is persisting in developing countries. In Rwanda, 9\% of mothers derived at home as reported in 2015 Demographic Health Survey. Delivering at home is associated with higher risk of maternal deaths. This study aims to investigate the rates of home delivery and associated factors. This study was a cross sectional study design with both qualitative and quantitative approaches. A convenience sampling was used to select 160 mothers for quantitative data. For qualitative data, 16 FGDs were conducted. Data were collected by using a structured questionnaire and interview guide. Quantitative data was analyzed using SPSS while qualitative data were thematically analyzed. A total of 160 mothers from 8 sectors of Kayonza district participated in the study. Of them $61.3 \%$ were aged less than 35 years, $70 \%$ were married, and $93.8 \%$ had attended primary education. The rate of delivering at home was $36.9 \%$ (deliver at home for two times or more). We found that mothers aged over 35 years were 3.5 times more likely to recurrently deliver at home than mothers aged between 15-35 years (OR=3.5; 95\% Cl: [1.80-6.96]; $p<0.001)$. The odds of having a recurrence of home delivery was found to be 4 times higher among mothers with limited transport facilitation (OR=4.0; 95\% Cl: [1.01$16.1] ; p=0.047$ ). Poverty, family conflicts, increase of teenage pregnancies, lack of health insurance, a lack of money to pay for a hospital services were mentioned as factors influencing recurrence of home delivery. There is a need to increase the support received by poor families in Rwanda.
\end{abstract}

Keywords: Home deliveries; Recurrence; Eastern province of Rwanda

\section{Introduction}

Globally, about four million of newborns die within their first week of life, and approximately 529,000 mothers lose their lives to pregnancy related causes [1]. Many births in low and middleincome countries are still occurring at home with no assistance of skilled attendants [2]. This has led to great concerns because women who face life-threatening problems during their pregnancy and/or delivery need adequate and accessible care. It has been documented that around $20-30 \%$ of neonatal deaths could be prevented by implementing skilled birth care services [3].

It was revealed that if a mother gives birth at home at the first time they are more likely to give birth at home again [4]. Home delivery is one of the public health threats, as the mother and the newborn are at a relatively high risk for several complications during delivery, disabilities and even death due to their vulnerable health status. Home deliveries and pregnancy related complications are among the main causes of maternal mortality. In 2017, the annual global estimate of maternal deaths was 295,000 , with $94 \%$ coming from less developed countries [5]. The majority of these deaths were preventable. In the same year, about two thirds of the estimated worldwide maternal deaths took place in Sub Saharan Africa [6]. A report from World Health Organization show that maternal mortality was 462 per 100000 in 2017 in low-income countries while SDGs target to reduce maternal mortality at or less than 70/100,000 live births by 2030 [5].
A qualitative study conducted in Burkina Faso confirmed that the two main barriers to facility-based delivery were geographical access in relation to conditions of roads and elevated transaction costs related to travel; and the sharing of fees that is still applied at the point of use [7]. A study conducted in Zambia revealed that home delivery is caused by sudden onset labor, transport difficulties to the closest health facility, poverty, as well as gender inequality, although it had a small percentage. Additionally, attitude is linked with home deliveries and staying at home alone when the labor starts [8]. In Ethiopia a study showed that among $67.2 \%$ of participants who gave birth at home, $89.6 \%$ were living in rural communities. The predictors of home deliveries included lack of education, older age, not watching $\mathrm{TV}$, and poverty [9].

In Rwanda, the rates of delivery at health facilities have increased from $80 \%$ in 2010 to $90 \%$ in $2014-2015$. As of $2018,91 \%$ of deliveries were carried out at the health facilities by skilled health professionals [6]. Even though the percentages of mothers who deliver at health facilities have increased overtime, there are still a significant number of women who deliver at home, therefore exposed to a high risk of pregnancy related complications. These complications include hemorrhage, hygiene related infections and even death.

A study conducted in Rwanda demonstrated that predictors of home delivery were high parity, residential place for rural woman, low level of education, lower household income, none or one antenatal
Austin J Womens Health - Volume 8 Issue 3 - 2021

Submit your Manuscript | www.austinpublishinggroup.com

Rutayisire et al. (C) All rights are reserved
Citation: Muhire A, Mukarwego B, Muhimba I, Bizimana GE, Bagwaneza T and Rutayisire E. Home Deliveries in Rwinkwavu District Hospital, Rwanda: Factor Associated with Recurrence of the Practice. Austin J Womens Health. 2021; 8(3): 1054. 
care visit and lack of antenatal counseling regarding pregnancy complications [10].

The Government of Rwanda has put in place various programs aiming to reduce maternal and child death such as the provision of health insurance to families that cannot afford to pay for their health insurances, decentralization of health facilities where each cell has a health post, strengthening community health workers service provision, etc.

Despite all these interventions that have been implemented to eliminate home deliveries, the number of home deliveries is still alarming. The prevalence of home deliveries in Rwanda was $9 \%$ and $11 \%$ in Eastern province was $11 \%$ in 2015. In 2019, a total 273 cases of home delivery were reported in Kanyonza District [11]. Therefore, it is of great importance to carry out this study in order to assess the reasons behind recurrence of home deliveries regardless all interventions that have been made available to strengthen birth assisted by healthcare professionals. The results from this study should help in establishing more realistic, effective and evidence based interventions needed to ensure that pregnant women deliver at health facilities.

\section{Materials and Methods}

\section{Study design and target population}

A cross sectional study design with both qualitative and quantitative approach was used to assess the factors associated with home deliveries and challenges faced by mothers after home delivery. Three groups of people, namely mothers who delivered at home, Community Health Workers (CHWs) who are responsible for those mothers as well as socio-economic and development officer at cell level were included in the study. For mothers, focus group discussions as well as in person interviews were conducted. This research was carried out in Kayonza district, specifically in Rwinkwavu District Hospital catchment area, and the study participants were selected among the mothers who delivered at home from August 2018 to July 2019. Kayonza District is located in Eastern province; and the district has 12 sectors.

\section{Sample size and sampling procedure}

The following formula was used to calculate the sample size $\mathrm{n}$ for mothers who delivered at home.

$$
\mathrm{n}=\mathrm{z}^{2^{*}} \mathrm{~N} / \mathrm{z}^{2}+\left(\mathrm{i}^{2^{*}}(\mathrm{~N}-1)\right)
$$

$\mathrm{Z}=$ Standard normal distribution curve value for $95 \% \mathrm{CI}$ which is 1.96

$$
\begin{aligned}
& \mathrm{N}=\text { Population size } \\
& \mathrm{I}=\text { Reduced margin of error } \\
& \mathrm{n}=160
\end{aligned}
$$

Therefore, a convenience sampling was used to select 20 up 30 mothers in each sector, to make a total of 160 mothers for quantitative data collection. For qualitative data, Focus Group Discussions (FGDs) with the mothers were carried out in all sectors prior to in person interviews. Two FGDs were conducted in each sector where one FGD was composed of the mothers while the other group will be of CHWs and SEDOs. For the latter, 8 members composed each
FGD: 4 CHWs and 4 sector officers in charge of social affairs A total of $32 \mathrm{CHWs}$ and 32 social affairs officers were selected for in person interviews and FGDs.

\section{Data analysis and ethical consideration}

Data were collected and cleaned to ensure its completeness and accuracy by using SPSS for quantitative data. A multivariate logistic regression model has been used to calculate odds ratio and the corresponding $95 \%$ confidence interval. A two tailed p-value of less than or equal to 0.05 has been used in order to state the statistical significance or not. Qualitative data was classified and coded into themes and concepts. Key information and quotations were synthetized and tabulated in order to know the information saturation.

The approval was obtained from Mount Kenya University Rwanda ethical review board. All data collected were treated anonymously. Neither the participants nor the health facilities' names or address appeared on the questionnaire. The participants' names and addresses were only used initially to identify their location, but the data collection was done anonymously. All confidential information was protected. There were no risks associated with the study. The participants benefited from the evidence based interventions that have been put in place upon this study's recommendations.

\section{Results}

\section{Socio-demographic characteristics of women who delivered at home}

The most respondents were aged between 15 and 35 years (61.3\%), 70\% were married, $93.8 \%$ had attended primary education, $87.5 \%$ were unemployed, $53.1 \%$ had monthly revenue under 30,000RWF, 35\% had husbands aged between over 35 years, and $54.4 \%$ of respondents' husbands had primary education level. More than a half of respondents (52.5\%) revealed that the distance between the nearest health facility and the mother's home lies between 2 and 5 kilometers. In average, each mother has given at least one birth $($ Mean $=1.43$ and Std. Deviation $=0.56), 60.0 \%$ of the respondents have between 1 and 3 children, $93.1 \%$ said that they have delivered at the health facility while $90.6 \%$ of them have delivered at home between 0 and 3 children. Less than half of mothers surveyed were in the second and third social category respectively with $38.8 \%$ and $43.8 \%$. Among them, $79.4 \%$ assumed they were enrolled in the family planning program. The majority $(83.6 \%)$ have subscribed to the health insurance. Christians were representing $26.3 \%$ of the total respondents versus $66.3 \%$ without religion (Table 1 ).

Findings indicate that $23.8 \%$ accepted that they have conflicts with their husbands. Merely $35.6 \%$ of mothers delivered at home said they have planned their pregnancies, $30.6 \%$ said they were with their neighbors at the time of delivery, $11.9 \%$ said being assisted with a Community Health Worker (CHW), 18.1\% were assisted with their mothers and $22.5 \%$ have not been assisted by anyone else at the time of delivery.

The majority (94.4\%) accepted they went at the health facility after delivering at home, $22.5 \%$ experienced complications after delivery where $15.6 \%$ were newborn-related complications and $6.8 \%$ were mother-related complications. Most of mothers surveyed agreed and strongly agreed that delivering at the health facility is very 
Table 1: Socio-demographic characteristics of women who delivered at home.

\begin{tabular}{|c|c|c|}
\hline Variables & $\begin{array}{l}\text { Frequencies } \\
\text { (n) }\end{array}$ & $\begin{array}{l}\text { Percent } \\
(\%)\end{array}$ \\
\hline \multicolumn{3}{|c|}{ Age of the mother delivered at home } \\
\hline 15-35 years & 98 & 61.3 \\
\hline Over 35 years & 62 & 38.3 \\
\hline \multicolumn{3}{|l|}{ Marital status } \\
\hline Single/unmarried & 48 & 30.0 \\
\hline Married & 112 & 70.0 \\
\hline \multicolumn{3}{|l|}{ Mother's education level } \\
\hline Primary education & 150 & 93.8 \\
\hline Secondary education & 10 & 6.2 \\
\hline \multicolumn{3}{|l|}{ Employment status } \\
\hline Unemployed & 140 & 87.5 \\
\hline Employed & 20 & 12.5 \\
\hline \multicolumn{3}{|l|}{ Monthly revenue [RWF] } \\
\hline Below 30,000RWF & 85 & 53.1 \\
\hline Over 30,000RWF & 6 & 3.8 \\
\hline No answer & 69 & 43.1 \\
\hline \multicolumn{3}{|l|}{ Husband's age } \\
\hline 21-35 years & 40 & 25.0 \\
\hline Over 35 years & 56 & 35.0 \\
\hline No stable husband & 64 & 40 \\
\hline \multicolumn{3}{|l|}{ Husband's education level } \\
\hline Primary education & 87 & 54.4 \\
\hline Secondary education & 9 & 5.6 \\
\hline University & 1 & 0.6 \\
\hline No answer & 63 & 39.4 \\
\hline \multicolumn{3}{|c|}{$\begin{array}{l}\text { Distance in kilometers between the nearest health } \\
\text { facility and the mother's home }\end{array}$} \\
\hline Less than $2 \mathrm{~km}$ & 22 & 13.8 \\
\hline Between 2-5km & 84 & 52.5 \\
\hline Above $5 \mathrm{~km}$ & 54 & 32.5 \\
\hline \multicolumn{3}{|c|}{ Number of children delivered [Births] } \\
\hline 1-3 children & 96 & 60 \\
\hline 4-6 children & 58 & 36.2 \\
\hline More than 6 children & 6 & 3.8 \\
\hline \multicolumn{3}{|c|}{ Number of children born at the health facility } \\
\hline 0-3 children & 149 & 93.1 \\
\hline More than 3 children & 11 & 6.9 \\
\hline \multicolumn{3}{|l|}{ Number of children born at home } \\
\hline 0-3 children & 145 & 90.6 \\
\hline More than 3 children & 15 & 9.4 \\
\hline \multicolumn{3}{|c|}{ Mother's social category [Ubudehe] } \\
\hline Category 1 & 23 & 14.4 \\
\hline Category 2 & 62 & 38.8 \\
\hline Category 3 & 70 & 43.8 \\
\hline Category 4 & 1 & 0.6 \\
\hline
\end{tabular}

\begin{tabular}{|l|c|c|}
\hline I do not know & 3 & 1.9 \\
\hline Mother enrolled in the family planning program & & \\
\hline Yes & 127 & 79.4 \\
\hline No & 33 & 20.6 \\
\hline Being subscribed to the health insurance & & \\
\hline Yes & 133 & 83.6 \\
\hline No & 27 & 16.4 \\
\hline Type of health insurance subscribed & & \\
\hline Mutuelle de santé/CBHI & 131 & 81.9 \\
\hline RAMA/MMI & 2 & 1.2 \\
\hline No insurance & 27 & 16.9 \\
\hline Mother's religion & & \\
\hline Christians & 42 & 26.3 \\
\hline Muslims & 4 & 2.5 \\
\hline No religion & 106 & 66.3 \\
\hline No answer & 8 & 5 \\
\hline
\end{tabular}

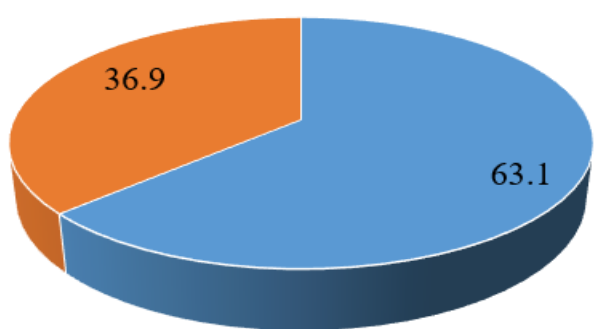

- One recurrence $\quad$ More than one recurrence

Figure 1: Rates of recurrence of home deliveries.

important respectively at $41.9 \%$ and $48.8 \%$. On the side of Antenatal Care (ANC) services, $33.8 \%$ of respondents revealed they attended the ANC services 3 times before delivery and $32.5 \%$ attended ANC 4 times (Table 2).

\section{Rates of recurrence of home deliveries}

Findings presented in above table revealed that $63.1 \%$ of the respondents have delivered once time at home versus $36.9 \%$ of mothers delivered more than once time at home (Figure 1).

Comparing the respondents' socio-demographic characteristics and recurrence of home delivery as presented in Table 3, findings revealed that mothers aged over 35 years were 3.5 times more likely to deliver at home recurrently than mothers aged between $15-35$ years $(\mathrm{OR}=3.5 ; 95 \% \mathrm{CI}:(1.80-6.96) ; \mathrm{p}<0.001)$ and mothers with husbands aged over 35 years were found likely to increase their odds of knowing a recurrence of home delivery than mothers with husband aged between 21-35 years $(\mathrm{OR}=3.4$; 95\% CI: $(1.38-8.54) ; \mathrm{p}=0.008)$ (Table 3).

\section{Socioeconomic factors and recurrence of home delivery}

There were three (3) Focus Group Discussions (FGDs) among community leaders and mothers delivered at home to capture detailed information on home deliveries in Rwinkwavu District 
Table 2: Family's characteristics of women who delivered at home.

\begin{tabular}{|c|c|c|}
\hline Variables & $\begin{array}{l}\text { Frequencies } \\
\text { (n) }\end{array}$ & $\begin{array}{l}\text { Percent } \\
\text { (\%) }\end{array}$ \\
\hline \multicolumn{3}{|c|}{ Existence of conflict in the family } \\
\hline Yes & 38 & 23.8 \\
\hline No & 56 & 35 \\
\hline No answer & 66 & 41.3 \\
\hline \multicolumn{3}{|l|}{ Pregnancy planned } \\
\hline Yes & 57 & 35.6 \\
\hline No & 101 & 63.1 \\
\hline \multicolumn{3}{|c|}{$\begin{array}{l}\text { Someone with the mother at the time of } \\
\text { delivery }\end{array}$} \\
\hline Her mother & 29 & 18.1 \\
\hline Mother-in-law & 7 & 4.4 \\
\hline My husband & 3 & 1.9 \\
\hline Neighbor & 49 & 30.6 \\
\hline Community health worker & 19 & 11.9 \\
\hline Other family member & 17 & 10.6 \\
\hline None & 36 & 22.5 \\
\hline \multicolumn{3}{|c|}{$\begin{array}{l}\text { After delivery, the mother or the newborn } \\
\text { experience any complications }\end{array}$} \\
\hline Yes & 36 & 22.5 \\
\hline No & 123 & 76.9 \\
\hline \multicolumn{3}{|l|}{ Complication experienced } \\
\hline Newborn-related complications & 11 & 15.6 \\
\hline Mother-related complications & 25 & 6.8 \\
\hline \multicolumn{3}{|c|}{$\begin{array}{l}\text { During your last pregnancy, number of ANC } \\
\text { services attended }\end{array}$} \\
\hline None & 12 & 7.5 \\
\hline One time & 14 & 8.8 \\
\hline Two times & 25 & 15.6 \\
\hline Three times & 54 & 33.8 \\
\hline Four times & 52 & 32.5 \\
\hline Above four times & 3 & 1.9 \\
\hline \multicolumn{3}{|c|}{ When attended ANC services, service provided } \\
\hline Not good & 3 & 1.9 \\
\hline Good & 103 & 64.4 \\
\hline Excellent & 42 & 26.3 \\
\hline No answer & 12 & 7.5 \\
\hline
\end{tabular}

Hospital Catchment area that support the information captured from the quantitative data.

First of all, community leaders were asked challenges did the mother face and led them to home delivery. The participant number 1 in the FGD1 pointed out that the main reasons why mothers give birth at home are poverty, which consequences in a lack of health insurance (Mutuelle de santé), a lack of money to pay for a hospital during delivery time and also travel expenses are very difficult.

Another participant number 2 from FGD1 said: "I get food after cultivate for someone in the village, he/she pay me 1000frw or food, if it is a money, we immediately used to buy food at that night because
I have 3 children, so how can I got the money for spend to the health facility during delivery it's impossible!”.

Participant number 5 of FGD1 added this: "Many mothers who give birth at home are poor, they are in the first and second grades of Ubudehe category, because they have no farmland, others are houses that the state has built for them and also they are the ones who continue to give birth at home and give birth for an indefinite period (Indahekana), they do not have the means to support them and not be leave where they will get the clothes of the baby after born or with them".

Participant number 5 from FGD2 stated this: "Many parents give birth at home because of the conflict they have with their husbands. When you tell your husband you are pregnant, men respond you that it is up to you, and you will find that the money he worked has been spent on alcohol and you have 4 or 5 children. So if I have young children and leave them at home I have nothing left and I have nothing to go to the clinics? How will I live? What are they left to eat"? The man who got me pregnant immediately denied me and told me that the pregnancy was not his and we would not live together, the pain (Agahinda) killed me and I had nothing to do. I stayed at my motherhouse, and you feel that it will not help you but you will become the enemy of the family. It's about starting to defend yourself and go out and cultivate people to see how you live, to get all things a mother needs I wouldn't take it off." said respondent 6, FGD1.

The participant number 2 from FGD3 added: "I travel more than 2 hours to reach the health center without any problems, so think when I am pregnant in a bad mood and you don't see a motorcycle immediately; those becomes the barriers to the mother who have given birth at home or on the way to the health centers".

A participant number 2 from FGD1 revealed this: "Local authorities are very involved in campaigns. When there is a meeting, they give us time to teach on maternal and child health programs. They play an important role in educating the public to buy health insurance (Mutuelle de santé), but when a mother gives birth at home they fine/punish them".

In the $2^{\text {nd }}$ FGD, participants assumed that local authorities are in charge of all health programs in general, and their role is to ensure that the health authorities do their job well where they are challenged and inform them and help them but there is no specialty of coming to monitor the mothers to give birth at the health facilities.

"When the elders of the village inform us of the person who refuses to attend ANC services, they are ordered to go there but often the next time she does not return, so the mother will give birth at home and no one will know, we all know that after she gave birth and we could do nothing but take her to the health facility immediately" said a participant 6 in FGD1.

Another participant number 4 in FGD1 mentioned this: "Village and cell leaders do nothing special to stop mothers giving birth at home because they are fined every day but no improvement/change because there are those who don't give it for the reason that they are incapable. There is no other option to the mother who is more at risk of home birth, not only to teach and encourage her to give birth at health facilities". 
Table 3: Socio-demographic characteristics and recurrence of home delivery.

\begin{tabular}{|c|c|c|c|c|c|}
\hline \multirow{2}{*}{ Variables } & \multirow{2}{*}{ Item } & \multicolumn{2}{|c|}{ Recurrence of Home Delivery } & \multirow{2}{*}{ P-value } & \multirow{2}{*}{ OR (95\% Cl) } \\
\hline & & One & $>$ One & & \\
\hline \multirow{2}{*}{ Age of the mother delivered at home } & $15-35$ years & $73(74.5)$ & $25(25.5)$ & Ref. & \\
\hline & Over 35 years & $28(45.2)$ & $34(54.8)$ & $<0.001$ & $3.5(1.80-6.96)$ \\
\hline \multirow{2}{*}{ Marital status } & Single/unmarried & $35(72.9)$ & $13(27.1)$ & Ref. & \\
\hline & Married & $66(58.9)$ & $46(41.1)$ & 0.095 & $1.8(0.89-3.93)$ \\
\hline \multirow{2}{*}{ Husband's age } & $21-35$ years & $31(77.5)$ & $9(22.5)$ & Ref. & \\
\hline & Over 35 years & $28(50.0)$ & $28(50.0)$ & 0.008 & $3.4(1.38-8.54)$ \\
\hline \multirow{3}{*}{ Distance with the nearest health facility } & Less than $2 \mathrm{~km}$ & 13(59.1) & $9(40.9)$ & Ref. & \\
\hline & Between 2-5km & $48(57.1)$ & $36(42.9)$ & 0.869 & $1.08(0.41-2.81)$ \\
\hline & Above $5 \mathrm{~km}$ & $39(75.0)$ & $13(25.0)$ & 0.175 & $0.4(0.16-1.38)$ \\
\hline \multirow{2}{*}{ Enrolled in the family planning } & Yes & $84(66.1)$ & $43(33.9)$ & Ref. & \\
\hline & Non & $16(50.0)$ & $16(50.0)$ & 0.094 & $1.9(0.89-4.28)$ \\
\hline \multirow{2}{*}{ Owned health insurance } & Yes & $86(64.7)$ & $47(35.3)$ & Ref. & \\
\hline & No & $15(57.7)$ & $11(42.3)$ & 0.5 & $1.3(0.57-3.15)$ \\
\hline \multirow{3}{*}{ Mother's religion } & Christians & $25(59.5)$ & $17(40.5)$ & Ref. & \\
\hline & Muslims & $3(75.0)$ & $1(25.0)$ & 0.551 & $0.4(0.04-5.11)$ \\
\hline & No religion & $68(64.2)$ & $38(35.8)$ & 0.6 & $0.8(0.39-1.71)$ \\
\hline
\end{tabular}

Contrarily, participants in FGD3 pointed out that local authorities do not play a big role in monitoring the pregnant mothers so that they do not give birth at home because this program are special to the CHWs and for health facilities but when we call them for help, sometimes they help us even though they are not available because of the amount of work they have.

To conclude to this issue of community leaders' role in reducing home deliveries, participant 1 in FGD1 stated this: "We, as CHWs, have a responsibility to monitor the maternal and children health and assisting mothers to delivery at health facilities; only those who give birth at home by intentionally the local leaders come and fine/punish them for being an example to others".

The last question but not least was about what should be the appropriate interventions to enhance health facility delivery and what strategies can be used to reduce home deliveries. Members of the FGD1 suggested that the method would help to reduce the number of births given at home is to improve the awareness of all people, especially those who are pregnant to be sure that pregnancy, childbirth and raising a child until adulthood are very expensive, so that it will help everyone prepared to give birth at the health facility and take good care of the one who will give birth.

"Mothers who give birth at home should be highly educated and mobilized to understand the importance of giving birth to the health facility because they have limited knowledge about health and development; because you see they give birth more time with don't care how the child will live" said participant 7 in FGD3.

Members from FGD2 recommended that what prevents parents from continuing to give birth at home requires the cooperation of all levels included the private sector, civil societies and local leaders so that all can educate and mobilize people to understand the importance of medical childbirth and help families live legally.
"The issue of parents giving birth at home is so serious that there is a need for the involvement of all levels, especially religions and churches, in educating parents to give birth to those they are able to raise, and men to take care of their families to avoid conflicts" said participant number 3 in FGD2.

This was complimented by another respondent who said this: "The parents to be able to give birth at the health facility, so they need to have the ability to pay for the medical expenses. Therefore, there are need of database of pregnant but unwed mothers, who are taught by the incompetent and are helped to prepare for childbirth at the clinics because he needs more than he can get" said the participant number 5 in FGD2.

In the FGD3, participants advised that pregnant mothers who are incapacitated should be screened at least to see how they can be helped to give birth at health facilities and receive the necessities instead of giving birth at home and health positivity should give the ability of maternity services for pregnant mothers because it is found in health centers build far away.

Respondent 7 in FGD3 said this: "Health centers are built very far of community, so health posts are closer to the community will increase the capacity to receive mothers who are about to give birth because they are the ones who do not have access to health facilities and an increase in the number of ambulances transporting mothers who have pregnancy problem from the villages".

\section{Discussion}

This study has documented the rate of recurrence of women who deliver at home in Rwinkwavu District Hospital catchment area of Rwanda. It has been found 36.9\% of mothers delivered more than once time at home. The researcher has not found any similar study conducted on the rate of recurrence of home delivery in order compare it with these study findings. Consequently, the researcher 
has found studies aimed to determine the recurrence of preterm birth and it associated factors among women with subsequent births.

The previous preterm birth, inter-pregnancy interval, preeclampsia were significantly associated with recurrence of preterm birth. Previous studies investigating factors associated with place of delivery, reported age of the mother as one of risk factor associated with home delivery $[12,13]$. In their analysis, both age of the mother and that of the partner were associated with the risk of home delivery. Their findings are consistent with that of this study where we found that mothers aged over 35 years were 3.5 times more likely to deliver at home, than mothers aged between $15-35$ years.

In a study conducted in India, mothers who have previously delivered successfully with no complications tend to deliver at home than the young new mothers. On the other hand, older women may belong to cohorts that are more traditional and thus be less likely to use modern facilities than young women [14].

Poverty was consistently reported as barrier to delivery at health facility in Kayonza District. This finding was in agreement with that conducted in rural and marginalized community in Tanzania [15]. However, it contradicts another study conducted in Nepal, which showed that economic factors insignificantly influence place of birth [16]. A number of studies conducted in Nigeria and Cambodia have linked marital status with home delivery $[17,18]$. Being a housewife coupled with poor or no education, harsh climatic conditions, inadequate public utilities including healthcare services, and transport system impacts negatively on women ability to access maternal services in West Pokot County in Kenya [19].

\section{Conclusion}

Recurrence of home deliveries is still a major public health problem. Understanding the recurrence rate of home delivery is critical as it provides information to healthcare providers and decision makers to guide the implementation of comprehensive health sector reforms to strengthen the public health system, with the aim of reducing maternal and newborn deaths. In this study, factors found to be associated with recurrence of home delivery in the study area were mother's age, husband's age and do not own basic equipment and transport means. Women delivered at home should be identified as high-risk group and regular visits should be done.

\section{Acknowledgement}

We would like to thank all study participated and research assistant who assisted during data collection.

\section{References}

1. WHO, UNICEF \& UNFPA. WHO Library Cataloguing-in-Publication Data Maternal mortality in 2005: estimates developed. World Health Organization. 2005.
2. Titaley $\mathrm{CH}$. Why do some women still prefer traditional birth attendants and home delivery? A qualitative study on delivery care services in West Java Province, Indonesia. BMC Pregnancy Childbirth. 2010; 10: 43.

3. Ayede A. Persistent mission home delivery in Ibadan: Attractive role Department of Paediatrics, University College Hospital, Ibadan. Ann Ibd. 2012; 10: 22-27.

4. Morison S. A phenomenological study of the homebirth experience. The couplrs perspective. 2016.

5. WHO. Maternal Mortality. 2019.

6. WHO, UNICEF \& UNFPA. Trends in maternal mortality 2000 to 2017 estimates by WHO, UNICEF, UNFPA, World Bank Group and the United Nations Population Division. World Bank Group and the United Nations Population Division. 2019

7. Manuela De Allegri JT. Understanding home delivery in a context of user fee reduction: A cross-sectional mixed methods study in rural Burkina Faso. BMC Pregnancy and Childbirth. 2015

8. Sinkamba. Factors Associated with Home Deliveries. Katondwe, Luangwa District: Women's Health Science Journal. 2019.

9. Chernet AG, et al. Home Delivery Practices and Associated Factors in Ethiopia. J Reprod Infertil. 2019; 20: 102-108.

10. Umurungi. Determinants of the utilisation of delivery services by pregnant women in Rwanda. WIReDSpace. 2010.

11. RHMIS. Home delivery. Rwinkwavu DH. 2019.

12. Nanang $M$ \& Atabila $A$. Factors predicting home delivery among women in Bosomtwe-Atwima-Kwanwoma district of Ghana: A case control study. Int J Med Public Health. 2014; 4: 287-291.

13. Van Eijik A, et al. Use of antenatal services and delivery care among women $\mathrm{n}$ in rural Western Kenya: a community based survey. J Reproductive Health. 2016; 3: 1-9.

14. Navaneetham K \& Dharmalingam A. Utilization of maternal health care services in Southern India. Soc Sci Med. 2016; 55: 1849-1869.

15. Mrisho et al. Factors affecting home delivery in rural Tanzania. Tropical Med Int Health. 2017; 12: 862-872.

16. Bolam A, Manandhar D, Shrestha P, Ellis M, Malla K \& Costello A. Factors affecting home delivery in the Kathmandu Valley, Nepal. Health Policy and Planning. 2018: 152-158.

17. Katung P. Socio-economic factors responsible for poor utilization of the primary health care services in a rural community in Nigeria. Nigerian Journal of Medicine. 2011: 28-29.

18. Yanagisawa S, Oum S \& Wakai S. Determinants of skilled birth attendance in rural Cambodia. Tropical Medicine and International Health. 2016: 238-251.

19. Otieno OJ. Factors Associated with Home Delivery in West Pokot County of Kenya. Advances in Public Health. 2015; 4: 7. 